Published in: Journal of Materials Science, 42 (2008) 4398-4405

\title{
Application of uniform design in optimisation of three stage ageing of Al-Cu-Mg alloys
}

\author{
N. Gao ${ }^{1}$, M.J. Starink, N. Kamp ${ }^{\text {a }}$ I. Sinclair \\ Materials Research Group, School of Engineering Sciences, University of \\ Southampton, Southampton, SO17 1BJ, United Kingdom \\ a currently at Manchester Materials Science Centre, UMIST, Manchester M1 7HS, UK
}

\begin{abstract}
The hardness variation and the behaviour of precipitation during the process of three stage ageing of three $\mathrm{Al}-\mathrm{Cu}-\mathrm{Mg}$ alloys were investigated using micro-hardness and differential scanning calorimetry (DSC). To facilitate the determination of the optimised heat treatment condition, a uniform design method was employed by which the influences of three stages interrupted ageing on the hardness and precipitation can be elucidated with a limited number of experiments. It is found that optimised heat treatment with maximum hardness can be achieved for non-stretched materials by applying the method of three stage ageing, but not for stretched T351 materials. The selection of a long initial Stage I and a suitable Stage II ageing time are important, and the Stage II ageing at $25^{\circ} \mathrm{C}$ shows more beneficial effect than ageing at $65^{\circ} \mathrm{C}$. The hardness during the three stage ageing is closely related to the amount of S phase formation.
\end{abstract}

Keywords: Ageing; Al-Cu-Mg alloys; hardness; DSC; uniform design

\footnotetext{
${ }^{1}$ Corresponding author. Tel.: +44-238-059-3396; Fax: +44-238-059-3016

E-mail address: n.gao@soton.ac.uk (N. Gao)
} 


\section{Introduction}

Al-Cu-Mg based alloys (2xxx series) are widely used in structural applications, in particular alloys with $\mathrm{Cu}: \mathrm{Mg}$ atomic ratio close to 1 are used extensively in the aerospace sector [1]. It is often thought that, once an aluminium alloy is artificially aged at an intermediate temperature (eg. T6 temper at $190^{\circ} \mathrm{C}$ ), the microstructure and mechanical properties remain unchanged for an indefinite period at lower temperature. However, recent observations made on an $\mathrm{Al}-\mathrm{Cu}-\mathrm{Mg}$ alloy with a much lower solute content using the technique of positron annihilation spectroscopy have indicated that vacancies may remain mobile at room temperature after these alloys were first aged at $180^{\circ} \mathrm{C}$ [2]. Such mobility will facilitate solute diffusion leading to possible further (secondary) precipitation at room temperature [3]. In fact, the subject of secondary ageing has been investigated for several aluminium alloys $[4,5,6,7]$, and it has been shown that so-called secondary precipitation may occur in several aluminium alloys when an interrupted low temperature secondary ageing is introduced through a three stage ageing process $[3,8,9]$. Recently, a three stage interrupted ageing treatment has been explored for several aluminium alloys [8]. This process shown schematically in Fig. 1 involves three stage ageing heat treatments [3]:

- Solutionizing and quenching

- Stage I: Ageing at elevated temperature $\left(T_{\mathrm{A}}>100^{\circ} \mathrm{C}\right)$ for a short period $\left(t_{\mathrm{A}}, 10\right.$ min $-8 \mathrm{~h})$, then quench to ambient temperature.

- Stage II: Ageing at low temperature $\left(T_{\mathrm{B}}\right.$, typically below $\left.70^{\circ} \mathrm{C}\right)$ for a long period $\left(t_{\mathrm{B}}\right.$, few hours to several weeks).

- Stage III: Ageing at elevated temperature $\left(T_{\mathrm{C}}=T_{\mathrm{A}}\right)$ to peak properties. 
In Stage I, $T_{\mathrm{A}}$ is similar to the ageing temperature normally used for $\mathrm{T} 6$ tempers, and time range from 10 minutes to 8 hours, depending on the specific alloy. After Stage I, the alloys are underaged and display hardness values 50-80\% of those corresponding to a full T6 temper. The alloys are then held (Stage II) for various periods at low temperature $\left(T_{\mathrm{B}}\right)$. Finally, $T_{\mathrm{C}}$ in Stage III is usually taken close to $T_{\mathrm{A}}$, and ageing is continued until peak hardness is reached. This complete treatment has been given the designation T6I6, signifying the standard T6 heat treatment is interrupted by a dwell period (I) at a lower temperature before resuming artificial ageing [3,8]. Alloy treated in this way can demonstrate simultaneous improvements in hardness, tensile properties and fracture toughness ranging from 5-30\%, depending on the composition

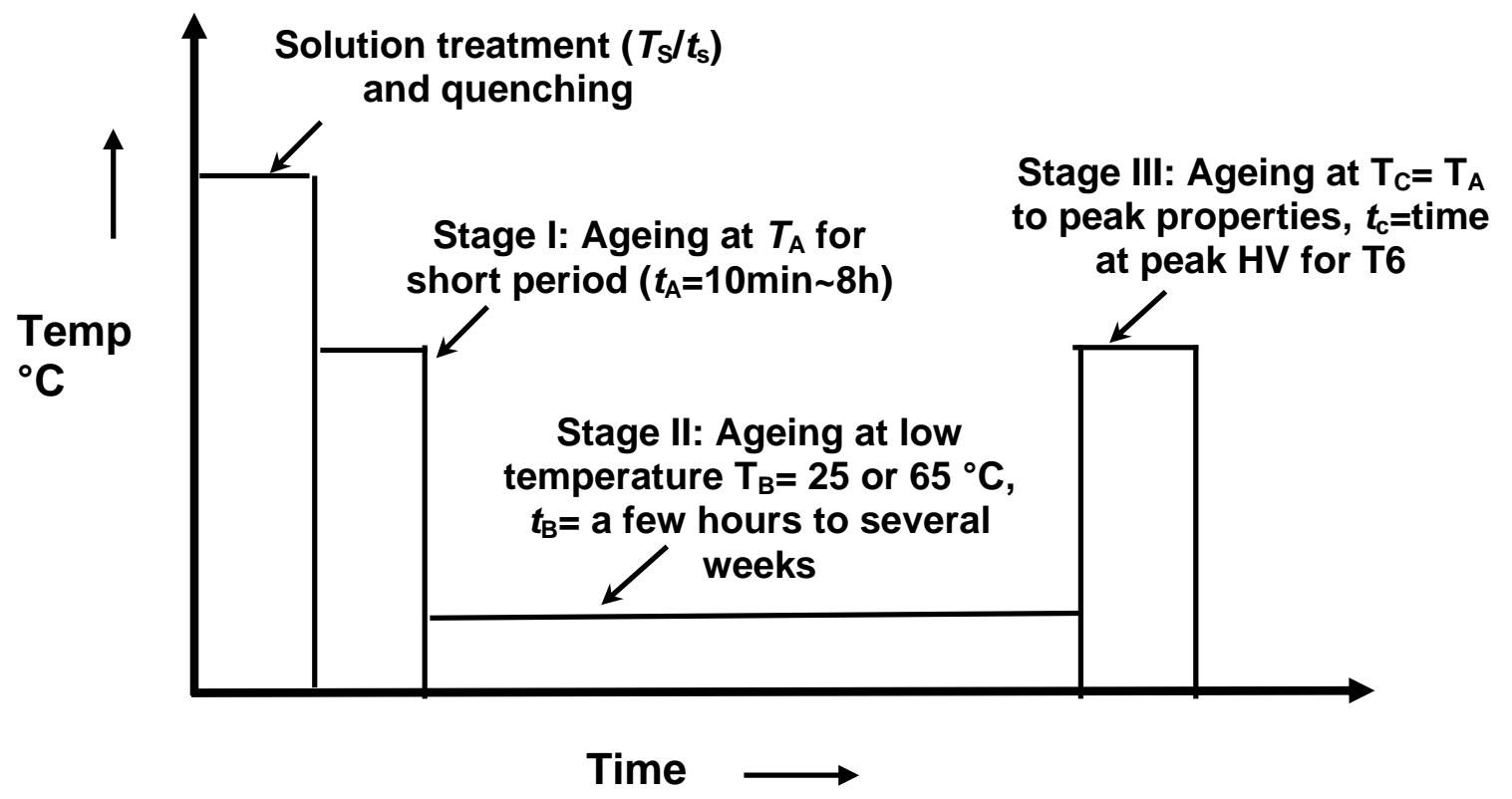

Fig. 1. General schematic representation of the three stages of T6I6 interrupted ageing treatment.

and specific processing conditions [3,8, ?]. These beneficial effects of interrupted ageing are believed to emanate from secondary precipitation occurring during the dwell period which can nucleate finely dispersed precipitates in the final aged microstructure $[8,10]$. The above experimental results have also revealed that the 
selection of the parameters of the three stage ageing treatment is critical for the optimzing heat treatment condition, which varies with different aluminium alloys.

In order to exploit the potential effect of the three stage ageing on the mechanical properties of aluminium alloys and to further understand this special ageing response for different aluminium alloys, three 2xxx alloys [11,12] were investigated by applying different three stage ageing treatment procedures. The objectives of this project are to investigate the effect of the three stage ageing on hardness, to find the optimising heat treatment process by achieving the maximum hardness through different ageing treatment and Vickers micro hardness testing. Differential scanning calorimetry analyses were carried out to examine the precipitation reaction at different ageing stages. To optimise the process parameters of the 3 stage heat treatment, a uniform design method was used in this work to investigate the influences of the process parameters on hardness and precipitation of three stage heat treatments.

\section{Experimental procedures}

Three Al-Cu-Mg-Mn alloys have been studied and their compositions are in Table 1. The composition of alloy 6 is close to the median composition of 2024. These alloys have been manufactured at QinetiQ, Farnborough, UK $[13,14]$. Billets were conventionally cast, stress relieved, homogenized, hot rolled to $20 \mathrm{~mm}$ thickness, solution heat treated, cold water quenched, stretched by $\sim 2.5 \%$ and then left at room temperature for a few months. Except for solution treatment temperatures, the processing was essentially the same for all alloys (optimum solution temperatures for 
individual alloys were identified via determination of the start temperature of (incipient) melting using DSC [15]).

Table 1. Chemical compositions of alloys (wt.\%).

\begin{tabular}{|c|c|c|c|c|c|}
\hline Alloy & Cu & Mg & Li & Zr & Mn \\
\hline A & 2.27 & 1.03 & 1.56 & 0.11 & 0.01 \\
\hline B & 4.34 & 1.37 & - & - & 0.42 \\
\hline C & 1.48 & 1.43 & 0.54 & 0.11 & - \\
\hline
\end{tabular}

Grain structure of the alloys in T351 condition was determined using electron backscatter diffraction (EBSD) on a Jeol JSM-6500 field emission gun scanning electron microscope (FEG-SEM) [ 16 ]. Thin foils for transmission electron microscopy (TEM) were prepared using a standard procedure: samples of $400 \mu \mathrm{m}$ thickness were punched, ground to $250 \mu \mathrm{m}$ and electro-polished using a 1/3 nitric acid, $2 / 3$ methanol solution held at $-20^{\circ} \mathrm{C}$ to $-30^{\circ} \mathrm{C}$, with a voltage of $25 \mathrm{~V}$. TEM observation was performed at 200kV using a Jeol JEM-2000FX.

The alloys have been conducted in the three stages of T6I6 ageing heat treatment. In constructing an experimental design model for optimising the heat treatment condition, only three dominant quantitative variables (i.e. the initial Stage I ageing time, $t_{A}$, the Stage II interrupted low temperature ageing temperature, $T_{B}$ and the Stage II ageing time, $t_{B}$ ) were taken into consideration. The other heat treatment parameters were taken as constant for each alloy throughout the three stage ageing, including solution temperature/time $\left(T_{S} / t_{S}\right)$, initial and final ageing temperature $\left(T_{A}\right.$ and $T_{C}$ ) and final ageing time $\left(t_{C}\right)$. The selections of these constant were based on the previous experimental results [11,13]. The uniform design method is employed in this study because its principle is to replace the complete combination of experimental 
parameters by using relatively fewer experiment trials uniformly distributed within the parameter space. These experiment trials are determined using the numbertheoretic method $[17,18]$ and mathematically proved to be a good approximation of the complete combination of experimental parameters [19]. For each of the three variables (factors), different treatment levels were incorporated (Table 2). Because

Table 2. The ageing parameters investigated

\begin{tabular}{|l|l|l|l|l|l|}
\hline $\begin{array}{l}\text { Parameter } \\
\text { (factors) }\end{array}$ & \multicolumn{5}{|c|}{ Treatment level (n) } \\
\hline & 1 & 2 & 3 & 4 & 5 \\
\hline Alloy & $\mathrm{A} / \mathrm{B}=\mathrm{C}$ & $\mathrm{A} / \mathrm{B}=\mathrm{C}$ & $\mathrm{A} / \mathrm{B}=\mathrm{C}$ & $\mathrm{A} / \mathrm{B}=\mathrm{C}$ & $\mathrm{A} / \mathrm{B}=\mathrm{C}$ \\
\hline $\begin{array}{l}\text { Stage I ageing } \\
\text { time, } t_{A}(\mathrm{~h})\end{array}$ & $1.0 / 2.5$ & $2.0 / 5.0$ & $2.5 / 6.3$ & $3.0 / 7.5$ & $4.0 / 10$ \\
\hline $\begin{array}{l}\text { Stage II ageing } \\
\text { time, } t_{B}(\mathrm{~h})\end{array}$ & 20 & 100 & 300 & 600 & 1200 \\
\hline $\begin{array}{l}\text { Stage II ageing } \\
\text { temperature, } T_{B} \\
\left(\mathrm{C}^{\circ}\right)\end{array}$ & 25 & 65 & & & \\
\hline
\end{tabular}

Table 3. Uniform design table $\left(U_{10}\left(5^{2} \times 2^{1}\right)\right)$

\begin{tabular}{|l|l|l|l|}
\hline Experiment No. & \multicolumn{3}{|c|}{ Number of factors } \\
\hline & $t_{A}(\mathrm{~h})$ & $t_{B}(\mathrm{~h})$ & $T_{B}\left(\mathrm{C}^{\circ}\right)$ \\
\hline 1 & 1 & 1 & 1 \\
\hline 2 & 1 & 2 & 2 \\
\hline 3 & 2 & 3 & 1 \\
\hline 4 & 2 & 4 & 2 \\
\hline 5 & 3 & 5 & 1 \\
\hline 6 & 3 & 1 & 2 \\
\hline 7 & 4 & 2 & 1 \\
\hline 8 & 4 & 3 & 2 \\
\hline 9 & 5 & 4 & 1 \\
\hline 10 & 5 & 5 & 2 \\
\hline
\end{tabular}

there are only two levels of variation (factor) for $t_{A}$, ten represented experiments were chosen by using the mix-level uniform design table $U_{10}\left(5^{2} \times 2^{1}\right)$ (or $U_{m}\left(q_{1}^{S_{1}} \times q_{2}^{S_{2}}\right)$ ), where $U$ represents uniform design, $m$ the total number of experiments, $q_{1}, q_{2}$ the 
number of levels of each factor, and $S_{1}, S_{2}$ the number of the factors. Therefore, $U_{10}\left(5^{2} \times 2^{1}\right)$ represents that there are total 10 experiments, with three factors (two with 5 levels and one with 2 levels) in these experiments. The uniform design table $U_{10}\left(5^{2} \times 2^{1}\right)$ is given in Table 3 and the full matrix of experiment is detailed in Table

4.

Table 4. Heat treatment conditions for the 10 selected experimental points and guided by the uniform design table

\begin{tabular}{|c|c|c|c|c|c|}
\hline $\begin{array}{l}\text { Experiment } \\
\text { No. }\end{array}$ & $T_{A}=T_{C}\left(C^{\circ}\right)$ & $\begin{array}{l}t_{A}(\mathbf{h}) \\
(\mathbf{A} / \mathbf{B} / \mathbf{C})\end{array}$ & $T_{B}\left(\mathbf{C}^{\circ}\right)$ & $t_{B}$ (h) & $\begin{array}{l}t_{C}(\mathrm{~h}) \\
(\mathrm{A} / \mathrm{B} / \mathrm{C})\end{array}$ \\
\hline & \multicolumn{2}{|c|}{ Stage I } & \multicolumn{2}{|c|}{ Stage II } & Stage III \\
\hline 1 & 190 & 2.5/1.0/2.5 & 25 & 20 & $15 / 6.0 / 15$ \\
\hline 2 & 190 & $2.5 / 1.0 / 2.5$ & 65 & 100 & $15 / 6.0 / 15$ \\
\hline 3 & 190 & $5.0 / 2.0 / 5.0$ & 25 & 300 & $15 / 6.0 / 15$ \\
\hline 4 & 190 & $5.0 / 2.0 / 5.0$ & 65 & 600 & $15 / 6.0 / 15$ \\
\hline 5 & 190 & $6.3 / 2.5 / 6.3$ & 25 & 1200 & $15 / 6.0 / 15$ \\
\hline 6 & 190 & $6.3 / 2.5 / 6.3$ & 65 & 20 & $15 / 6.0 / 15$ \\
\hline 7 & 190 & 7.5/3.0/7.5 & 25 & 100 & $15 / 6.0 / 15$ \\
\hline 8 & 190 & 7.5/3.0/7.5 & 65 & 300 & $15 / 6.0 / 15$ \\
\hline 9 & 190 & $10 / 4.0 / 10$ & 25 & 600 & $15 / 6.0 / 15$ \\
\hline 10 & 190 & $10 / 4.0 / 10$ & 65 & 1200 & $15 / 6.0 / 15$ \\
\hline
\end{tabular}

No. Variables (factors) investigated by the uniform design method in bold format

$T_{A}=T_{C}=190^{\circ} \mathrm{C}$ was chosen because previous work on these alloys indicated that a satisfactory balance in properties can be achieved by ageing alloys at $190^{\circ} \mathrm{C}[11,12]$. Initial Stage I ageing times, $t_{A}$ is specific to each alloy and was determined with the aid of strength predications using the model described in Ref. [20]. The Stage I and III ageing of the alloys 3 and 9 took longer time in $t_{A}$ and $t_{C}$ than the alloy 6 because it has been found that these two alloys took longer time to reach peak hardness due to the Li addition in the alloys $[11,12]$. To start with the T6I6 heat treatment, all samples were freshly solution treated at 513, 495 and $505^{\circ} \mathrm{C}$ respectively for alloys 3, 6 and 9, 
and subsequently quenched into water at room temperature before the further ageing treatments commenced.

Ageing response was studied by performing Vickers hardness tests on aged specimens at different ageing stages. The hardness values were obtained from surfaces ground with \#1200 grade SiC-paper. Four indentations were made on each specimen with a 1 $\mathrm{kg}$ load and a mean hardness is reported. Samples aged at different stages of T6I6 were studied by DSC in a Perkin-Elmer Pyris 1 calorimeter. Samples were discs (5 mm diameter and approximately $1 \mathrm{~mm}$ thickness) that were machined prior to heat treatment. Scanning over the temperature range $5-540^{\circ} \mathrm{C}$ at a constant heating rate of $10^{\circ} \mathrm{C} / \mathrm{min}$ was performed. To correct for baseline drift and heat capacity of the sample and reference, a two stage baseline correction was performed [15].

\section{Results and discussion}

\section{1 Microstructure before ageing}

All the alloys at the as-received T351 condition have a plate-shaped grain structure, although variations in recrystallization level and grain size are evident. EBSD maps of the grain structure for the three alloys are presented in Fig. 2, in which the higher angle grain boundaries (misorientations $>12^{\circ}$ ) are displayed by thick dark lines and low angle grain boundaries (misorientations 2 to $12^{\circ}$ ) by thin grey lines. The Mn- 

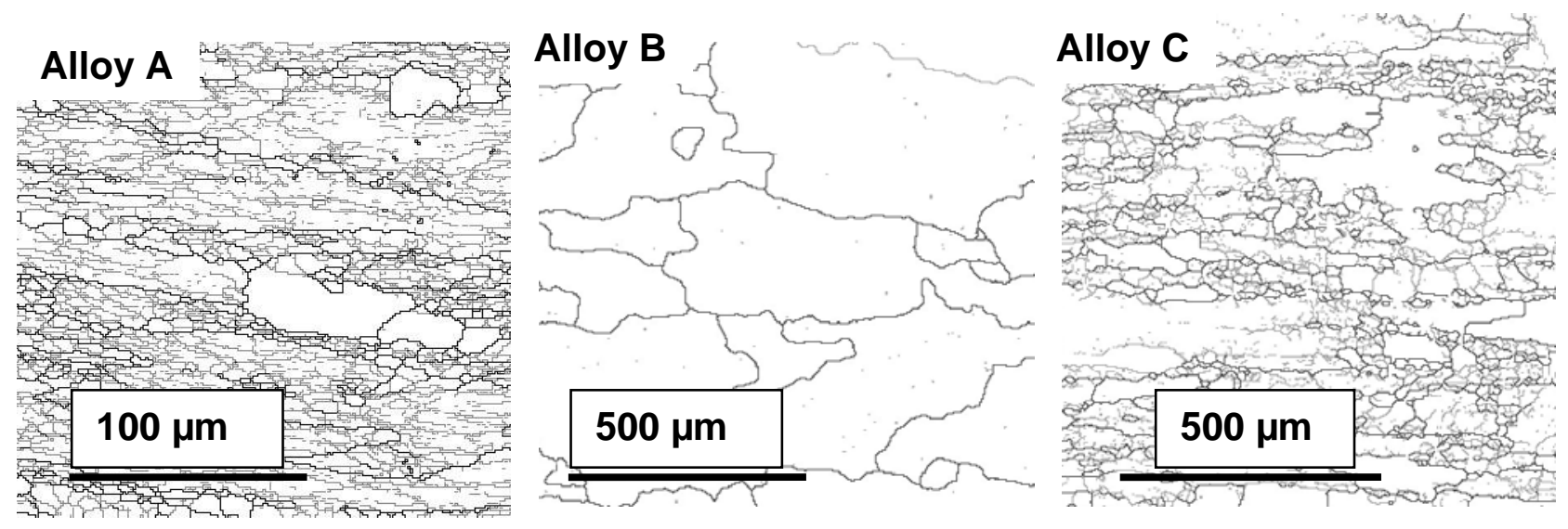

Fig. 2. EBSD maps of TS sections of alloys A, B and C - showing higher angle grain boundaries $\left(>12^{\circ}\right)$ by dark lines and lower angle grain boundaries $\left(2 \sim 12^{\circ}\right)$ by grey lines.

containing alloy 6 was predominantly found to be recrystallized with coarse grains (145 $\mu \mathrm{m}$ ), whilst the Zr-containing alloys 3 and 9 were only partially recrystallized with smaller grain sizes with average grain size of 8 and $40 \mu \mathrm{m}$. TEM analysis reveals that the Zr containing alloys contains many small sub-grains (Fig. 3) and there are many dislocation lines and loops for as-received T351 samples. The dislocations result from the stretching after solution treatment and the loops are generally caused by condensation of quenched in vacancies.

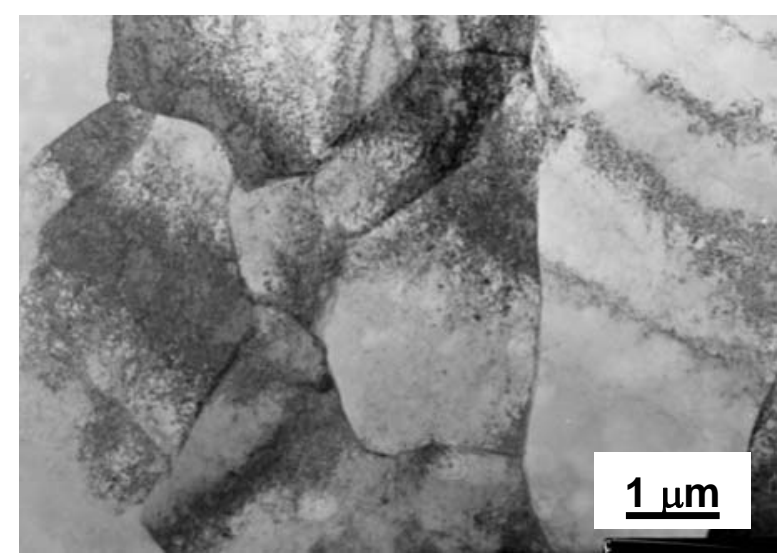

Fig. 3. TEM micrograph of the alloy A at T351 condition. 


\subsection{Hardness tests}

Fig. 4 shows the hardness results after the three stage of T6I6 ageing heat treatment. There are two peaks for the alloy 3, respectively for the No. 3-5 samples and the No. 8-9 samples. Among them, the No. 9 sample $\left(t_{A}=10 / 4.0 / 10 \mathrm{~h}, T_{B}=25^{\circ} \mathrm{C}\right.$, and $t_{B}=$ $600 \mathrm{~h})$ has the highest hardness value compared with the other heat treatment conditions. A maximum of 9.2\% increase in hardness can be seen from $120 \mathrm{Hv}$ of the No. 2 sample to $131 \mathrm{Hv}$ of the No. 9 sample. For the alloy 6, the No. 3 and the 5 samples have relatively high hardness values, but still it is the No. 9 sample which possesses the best hardness. A maximum of $7.8 \%$ increase in hardness has been achieved from the No. 1 (142 Hv) to the No. 9 (153 Hv) samples for the alloy 6. The No. 4-5 samples provide relatively high hardness value for the alloy 9, but still less than the No 9 sample, which shows a 7.1\% increase in hardness compared with the No. 1, 2 and 8 samples. Overall, the No. 9 experimental condition gives the best result for all the three alloys.

In order to clearly see which ageing stage has more significant effect on hardness variation, the original experimental data in different ageing stages have to be carefully studied. Therefore, the Stage I ageing time has been plotted against the Hv values after Stage I ageing (Fig. 5), which demonstrates that the hardness invariably increases with the increase of Stage I ageing time. Fig. 6 shows the Stage II ageing time against hardness after Stage III ageing. It can be seen that there are similar trends in the change of the final Stage III hardness for the alloys 3 and 9 during Stage II ageing between $25^{\circ} \mathrm{C}$ and $65^{\circ} \mathrm{C}$. That is, in most cases, the Stage III hardness gradually increases with the increase of Stage II ageing time until $600 \mathrm{~h}$, and then 

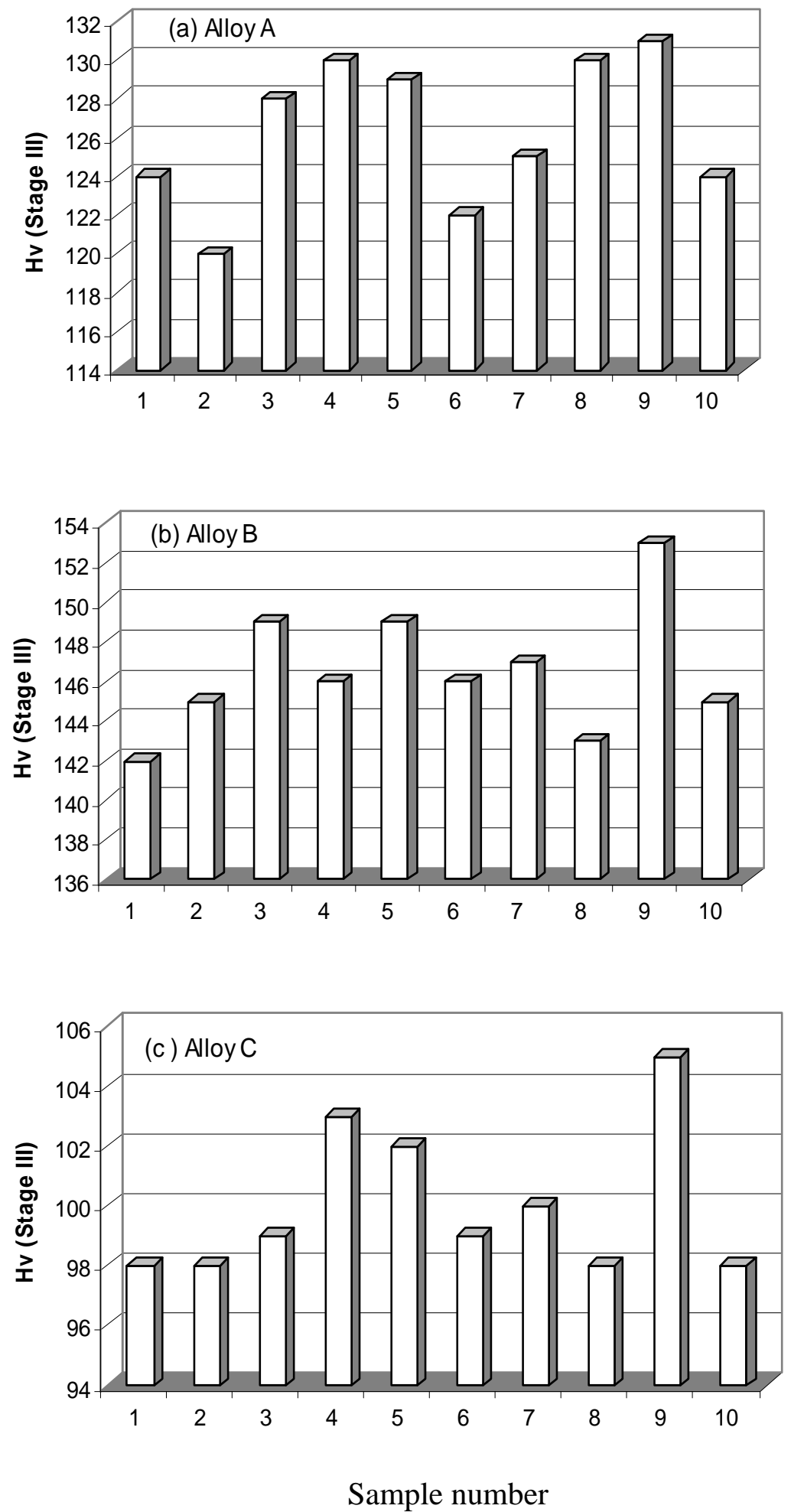

Fig. 4. Comparison of Hv results from different T6I6 heat treatments for the three alloys.

Stage III hardness starts to decrease. The same trend is seen for the alloy 6 during the Stage II ageing at $25^{\circ} \mathrm{C}$, but not at $65^{\circ} \mathrm{C}$. In general, all of them display two similar 
features: (1) Stage II ageing at 600 h (No. 9 sample) always shows the maximum hardness among the all of samples; (2) Stage II ageing at $25^{\circ} \mathrm{C}$ mostly provides a higher hardness than ageing at $65^{\circ} \mathrm{C}$. It must be pointed out that the order of the sample numbers, shown at the bottom of the Fig. 6, either ageing at $25^{\circ} \mathrm{C}$ or $65^{\circ} \mathrm{C}$, is different with the order of increasing Stage II ageing time due to the specific characteristics of the uniform design method. It has been noted that the No. 9 sample has the longest Stage I ageing time and the second longest Stage II ageing time, therefore, it can be concluded that that a longer initial Stage I and Stage II ageing times $\left(t_{A}\right.$ and $\left.t_{B}\right)$ are important and the ageing at $65^{\circ} \mathrm{C}$ obviously does not produce better results than ageing at $25^{\circ} \mathrm{C}$ during the Stage II low temperature ageing.

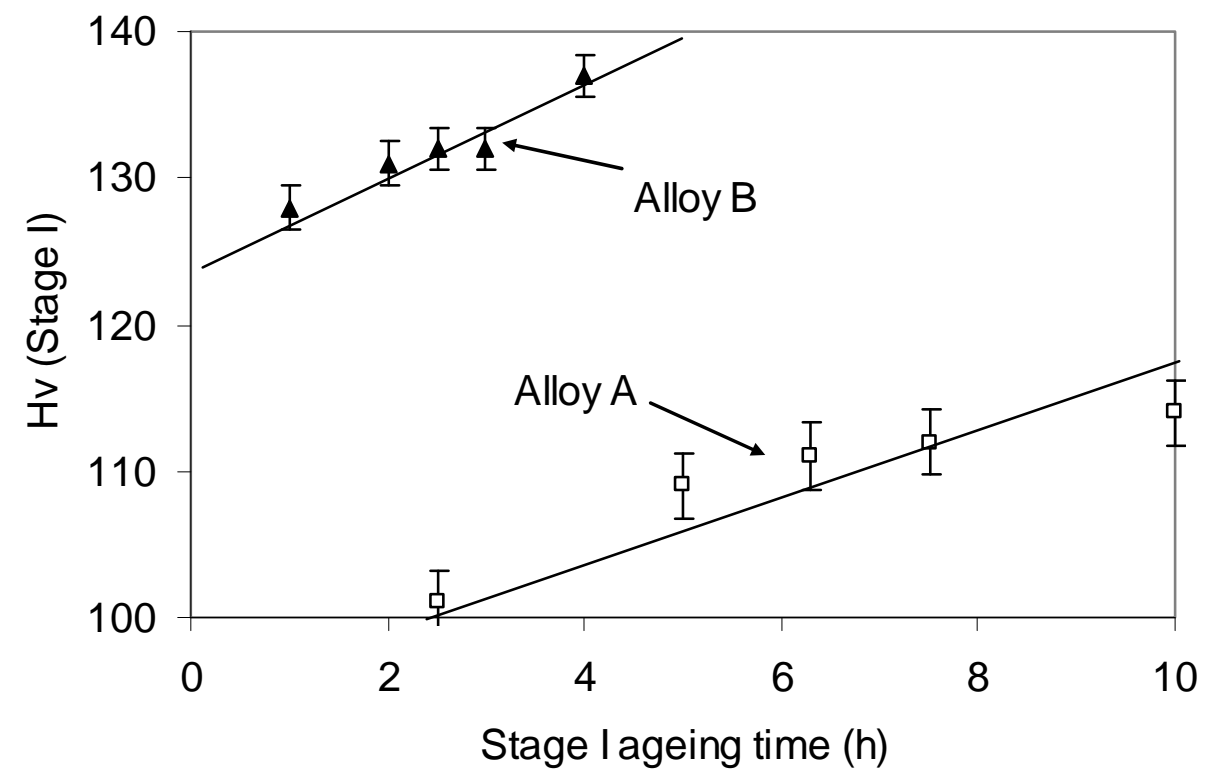

Fig. 5. Effect of Stage I ageing time on Stage I hardness value for alloys A and B.

Considering both No. 9 and No. 10 samples have the same Stage I ageing time, it is interesting to see that No. 9 sample has distinct higher hardness than No. 10 sample, though the former has a short Stage II ageing time $(600 \mathrm{~h})$ than the later (1200 h) but different Stage II ageing temperature, which means that Stage II ageing at $25^{\circ} \mathrm{C}$ (No. 
9) is more beneficial than at $65^{\circ} \mathrm{C}$ (No. 10). It is possible the decrease of the hardness in the No. 5 sample (Stage II ageing at $25^{\circ} \mathrm{C} / 1200 \mathrm{~h}$ ) is due to the reduction of Stage I ageing time (6.3/2.5/6.3), compared with No. 9 (10/4.0/10) samples for the three alloys.

For the as-received T351 and freshly quenched alloys, additional one step ageing heat treatments have been carried out for the three alloys, respectively heating up to peak hardness with the previous designed time $\left(190^{\circ} \mathrm{C} / 15 \mathrm{~h}\right.$ for alloys 3 and 9 , and $190^{\circ} \mathrm{C} / 6 \mathrm{~h}$ for alloy $6[11,12,21]$. A comparison of the hardness values between the best T6I6 results (No 9. sample) from the three stage ageing and the results of one step ageing for T351 and T6 tempers is shown in Fig. 8, which demonstrates that the hardness values of the No. 9 sample after three stage ageing are higher than the T6 temper for all of the three alloys, respectively increasing hardness of $6.5 \%, 10.1 \%$ and 9.4\% for the alloys 3, 6 and 9. However, only the alloys 3 and 9 show a slightly improvement of the harness after the No. 9 three stage ageing, compared with the one step aged T351 alloys, but there is no improvement in hardness for the alloy 6 . This means that the No. 9 heat treatment works better for certain 2xxx alloys than others. The different behaviours in hardness between the three alloys indicate that the outcome of the T6I6 three stage ageing heat treatment may be sensitive to alloy composition.

\subsection{DSC analysis}

Fig. 8 shows the DSC curves of the alloys 3, 6 and 9 in the conditions of before and after different stages of ageing for the No. 9 sample ageing process, together with the 

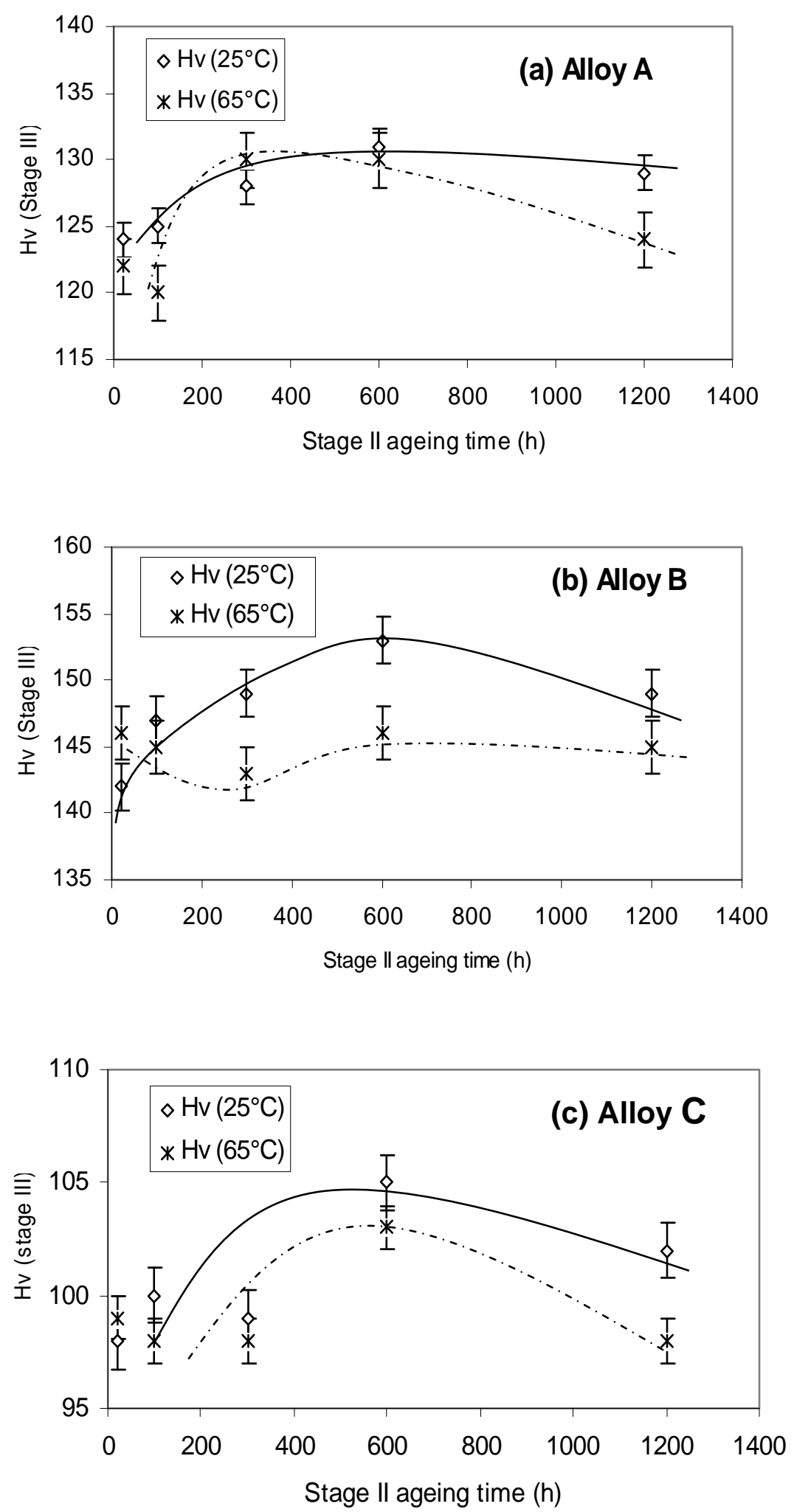

Order of sample number $\left(25^{\circ} \mathrm{C}\right): 1,7,3,9,5 \rightarrow$

Order of sample number $\left(65^{\circ} \mathrm{C}\right): 6,2,8,4,10 \rightarrow$

Fig. 6. Effect of Stage II ageing time on Stage III hardness value ageing for the three alloys. (Note: the order of the samples numbers is different with the increase of Stage II ageing time due to the specific characteristics of the uniform design method.) 

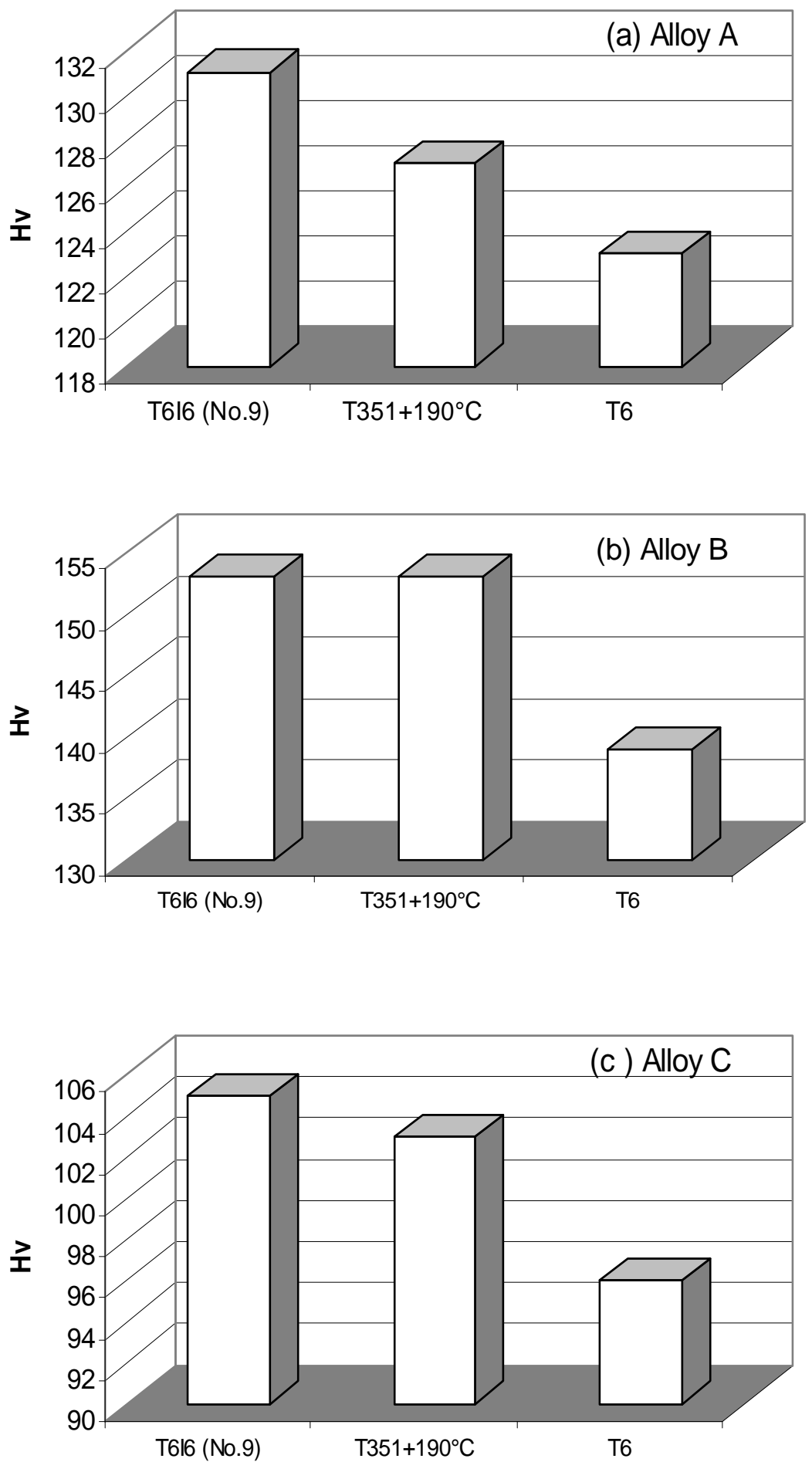

Fig. 7. Comparison of hardness results between best result from T6I6 (No. 9 sample) and the results of one step ageing for T351 and for fresh quenched alloys (T6 temper). 
fresh quenched sample. In general, freshly quenched samples have two precipitation peaks, one round $50-150^{\circ} \mathrm{C}$ which is related to zone/cluster formation, and another peak around $250-350^{\circ} \mathrm{C}$ due to S formation [22]. After initial Stage I ageing, alloy 3 still show a small peak from zone/cluster formation. This is because there is higher lithium content in alloy 3, compared with other alloys, which delays the zone/cluster precipitation process [12]. This peak disappears for the alloys 6 and 9. This implies that zone/cluster formation basically has been completed during the Stage I ageing process for the alloys 6 and 9 . An obvious reduction of $S$ formation peak and an increase of S dissolution area after initial Stage I ageing indicate that substantial S phase has been formed during the Stage I ageing. All the DSC curves demonstrate that the alloys are not stabilized after initial Stage I ageing, and further S precipitation follows in the subsequent Stage II and III ageing processes. The time interval for the reduction of S phase formation effect coincides with the time interval for the increase in hardness, shown in Figs. 5 and 6, indicating that the formation of $\mathrm{S}$ phase is responsible for the increase in hardness. It is interesting to note that the size of the zone/cluster dissolution areas also changes with the ageing process, but trends differ amongst the three alloys.

A comparison of DSC curves of the alloy 6 between T351, T351 $+190^{\circ} \mathrm{C} / 6 \mathrm{~h}$, after Stage I, and after Stage III ageing for the No. 9 sample is shown in Fig. 9, which reveals two apparent differences between them. Firstly, the $\mathrm{S}$ formation peak temperature in T351 sample $\left(257^{\circ} \mathrm{C}\right)$ has moved to higher temperature in the three stage ageing samples $\left(275^{\circ} \mathrm{C}\right)$. This behaviour has been seen in other DSC works on similar aluminium alloys which shows the stretching by 2 3\% after quenching causes 

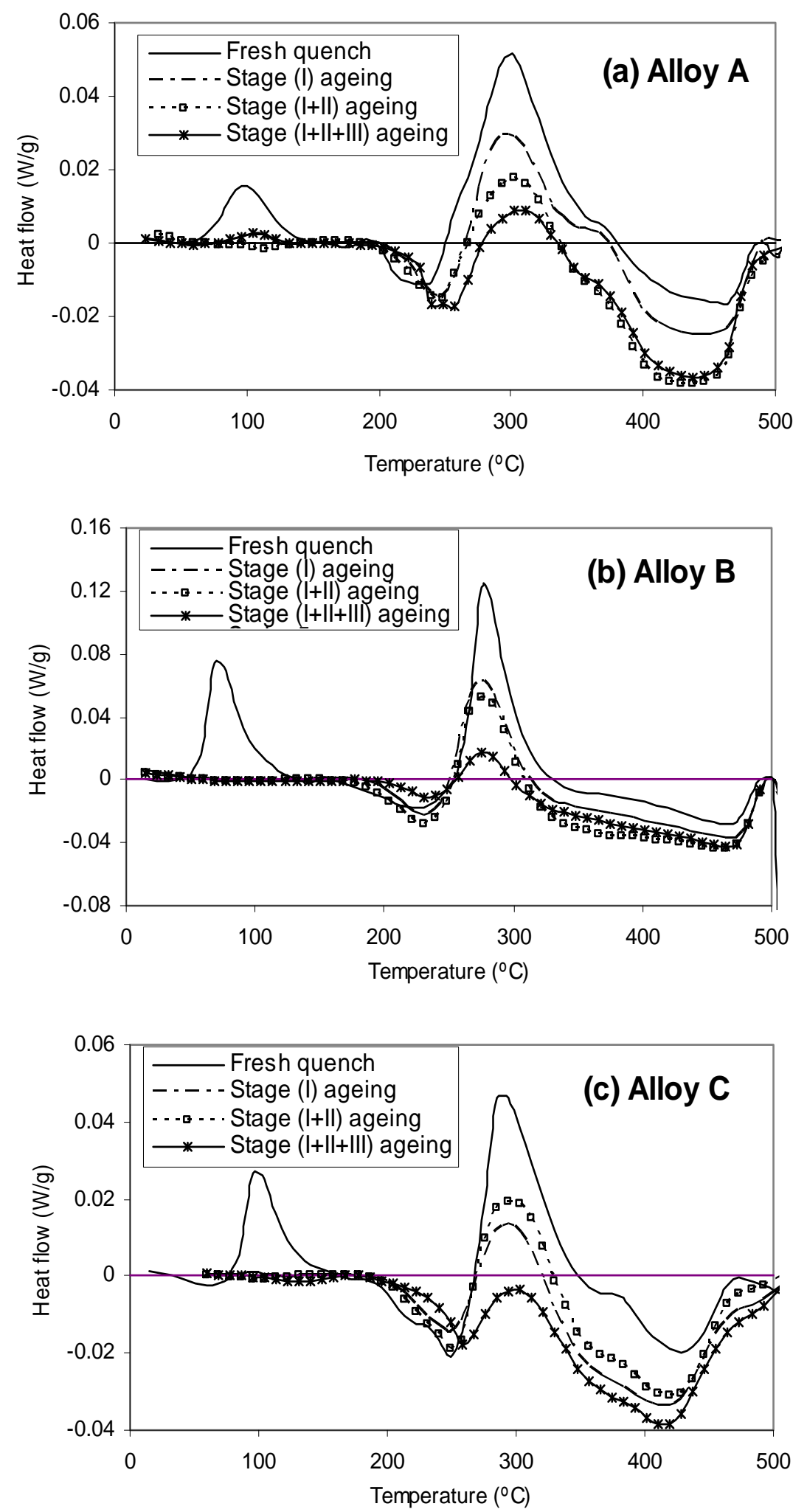

Fig. 8. DSC curves of alloys A, B and C after different stages of ageing (No. 9 sample). 
the S precipitation peak to shift to a lower temperature by about $10^{\circ} \mathrm{C}$ [23]. This can be explained by the dislocation introduced by stretching, which accelerate the $\mathrm{S}$ precipitation. The dislocations act as preferential nucleation sites to facilitate heterogeneous nucleation of S phase and as short circuit diffusion paths to accelerate the precipitation rates by dislocation core diffusion. Secondly, the S formation peak disappears very quickly for the $\mathrm{T} 351+190^{\circ} \mathrm{C} / 6 \mathrm{~h}$ sample which means that $\mathrm{S}$ phase formation has been completed after $190^{\circ} \mathrm{C} / 6 \mathrm{~h}$ ageing. The $190^{\circ} \mathrm{C} / 6 \mathrm{~h}$ ageing also causes the zone/cluster dissolution effect to disappear for the T351 sample. However, the $\mathrm{S}$ formation peak and zone/cluster cluster dissolution area in the three stage ageing samples still exists, although the total accumulated ageing time of the three stage ageing at $190^{\circ} \mathrm{C}$ already reach up to 10 hours for the alloy 6 . This characteristic probably can be explained that the immediate stage I initial ageing after fresh quenching seems to have a very strong tendency to delay the S phase precipitation and zone/cluster dissolution process.

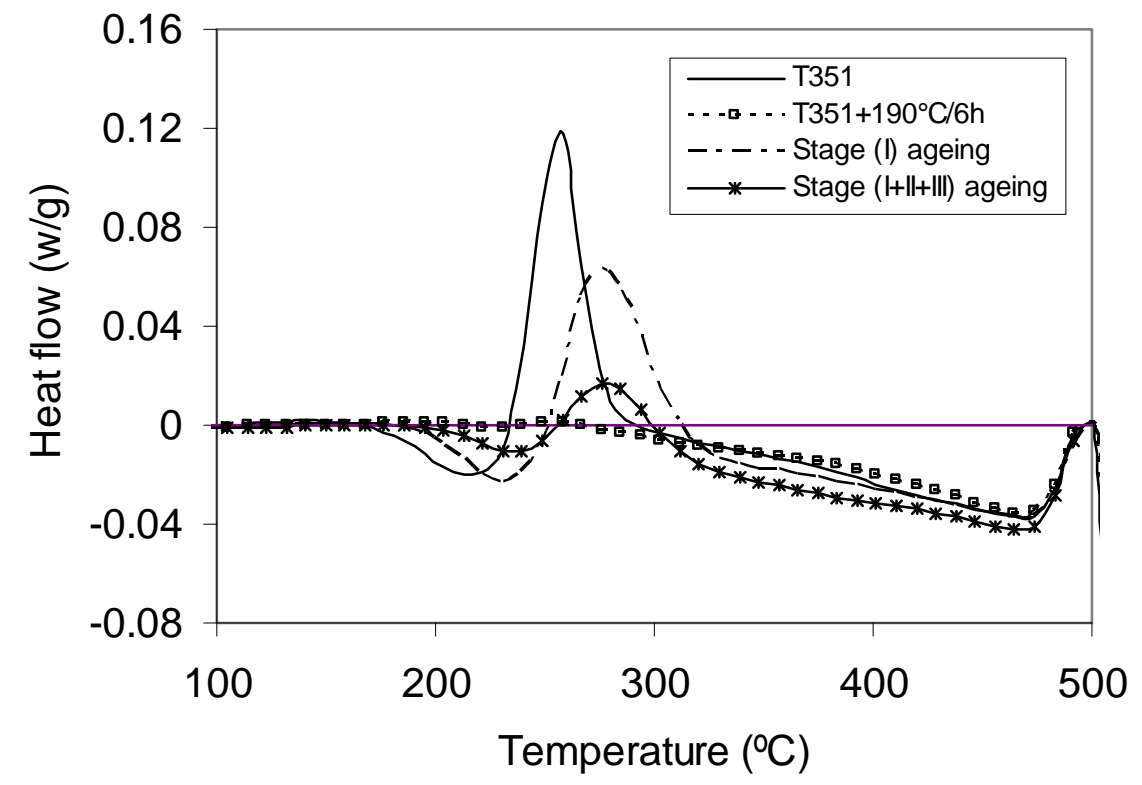

Fig. 9. Comparison of DSC curves of alloy B between T351 and after different stages of ageing (No. 9 sample). 
From the preliminary results of this study, it seems that the three stages of T6I6 process indeed improve hardness of T6 tempered alloys, but not for T351 alloys. This means that T6I6 and stretching do not seem complementary. Two reasons may be put forward to explain this: (1) Stretch reduces vacancy levels and provides heterogeneous precipitation sites; (2) Rapid heterogeneous precipitation in the first step ageing may limit driving force for low temperature precipitation for T351 alloys, whilst low vacancy concentration will limit diffusivity. However, this study is not a comprehensive study of stretched/unstretched condition in relation to T6I6 treatment and further analysis of stretched and unstretched alloys, and T6I6 optimisation are clearly of interest for further work. Detailed microstructural analysis, such as TEM and EBSD, need to be conducted in order to more clearly explain the strengthening mechanism from the early precipitation phases through the T6I6 three stage ageing, especially to examine the fine precipitation which is claimed to be the main cause in improvement of mechanical properties of alloys $[8,10]$.

? Add some ideas about second aging principles?

\section{Conclusions}

1. The uniform design method is shown to be useful in optimising the variables of the studied three stage heat treatment for Al-Cu-Mg alloys.

2. The application of T6I6 temper to these alloys indicates that it can increase the hardness by $7-9 \%$ as compared to the T6 temper (un-stretched), but not for stretched T351 materials. The extent of improvement in hardness from the T6I6 three stage ageing heat treatment may be sensitive to alloy composition. 
3. The selection of a long initial Stage I and a suitable Stage II ageing time is important. In the most cases, the Stage II ageing at $25^{\circ} \mathrm{C}$ shows more beneficial effect than ageing at $65^{\circ} \mathrm{C}$.

4. DSC analysis indicates that the hardness during the three stage ageing is closely related to the S phase content. 


\section{Reference}

1 M.J. Starink, N. Gao, L. Davin, J. Yan, A. Cerezo, Phil Mag. 85 (2005) 1395-1417.

2 A. Somoza, A. Dupasquier, I.J. Polmear, P. Folegali, R. Ferragut, Phys. Rev. B 61 (2000) 14454-14463.

3 R.N. Lumley, L.J. Polmear, A.J. Morton, Proceedings from Materials Soultions Conference, 5-8 November, Indianapolis, IN, ASM International, 2001, p 248254.

4 A. Dupasuier, R. Ferragut, P. Folegati, M. Massazza, G. Riontino, A. Somoza, Materials Science Form 396-402 (2002) 738-788.

5 C.E. Macchi, A. Somoza, A. Dupasquier, I.J. Polmear, Acta Mater. 51 (2003) 5151-5158.

6 G. Riontino, M. Massazza, Philosophical Magazine 84 (2004) 967-981.

7 R.N. Lumley, L.J. Polmear, A.J. Morton, Mater Sci Techno. 21 (2005) 1025-1032.

8 R.N. Lumley, L.J. Polmear, A.J. Morton, Materials Science Form 396-402 (2002) 893-898.

9 R.N. Lumley, A.J. Morton, L.J. Polmear, Acta Mater. 50 (2002) 3597-3608.

10 J. Buha, R.N. Lumley, P.R. Munroe, A.G. Crosky, in: J.F. Nie, A.J. Morton, B.C. Muddle (Eds.), Proc. 9th Int. Conf. on Aluminium Alloys, Brisbane, Australia, 25 August 2004, Institute of Materials Engineering Australasia Ltd, Australia, p 1167-1172.

11 N. Kamp, M.J. Starink, I. Sinclair, N. Gao, P.J. Gregson, P.D. Pitcher, S. Gardiner, in: J.F. Nie, A.J. Morton, B.C. Muddle (Eds.), Proc. 9th Int. Conf. on Aluminium Alloys, Brisbane, Australia, 2-5 August 2004, Institute of Materials Engineering Australasia Ltd, Australia, p 369-375.

12 M.J. Starink, N. Gao, N. Kamp, S.C. Wang, P.D. Pitcher, I. Sinclair, Mater. Sci. Engng. A (2005) in press.

13 M.J. Starink, I. Sinclair, N. Gao, N. Kamp, P.J. Gregson, P.D. Pitcher, A. Levers, S. Gardiner, Materials Science Form 396-402 (2002) 601-606.

14 N. Gao, M.J. Starink, L. Davin, A. Cerezo, S. Wang, P.J. Gregson, Mater Sci Techn. 21 (2005) 1010-1018.

15 M.J. Starink, Int Mater Rev 49 (2004) 191-226.

16 M.J. Starink, S.C. Wang, Acta Mater 51 (2003) 5131-5150.

17 K.T. Fang, Y. Wang, Number-Theoretic Methods in Statistics, Chapman and Hall, London, 1994.

18 R. Li, D.K.J. Lin, Y. Chen, Int. J. Materials and Product Technology 20 (2004) 101-114.

19 K.T. Fang, Acta Math Appl Sin. 3 (1980) 362-372.

20 M.J. Starink, J. Yan, in: M. Tiryakioglu, L.A. Lalli (Eds.), Proc. ASM Materials Solutions Conf. 2003, 1st International Symp. on Metallurgical Modeling for Al Alloys, October 12-15, 2003, Pittsburgh, PA, USA, ASM Intern., Materials Park, Ohio, USA, 2003, p 119-126.

21 N. Kamp, N. Gao, M.J. Starink, I. Sinclair, Innovation of age forming through development of novel damage tolerant alloys, Research Report, University of Southampton, 2004.

22 M.J. Starink, S.C. Wang, Int Mater Rev 50 (2005) 193-215. 
23 J. Yan, Strength Modelling of Al-Cu-Mg Type Alloys, MPhil/PhD Transfer Thesis, University of Southampton, UK, 2004. 